\title{
Racial Disparities and Similarities in Post-Release Recidivism and Employment Among Ex-prisoners with a Different Level of Education
}

\author{
SUSAN KLINKER LOCKWOOD \& JOHN M. NALLY \\ Indiana Department of Correction \\ TAIPING HO \\ Ball State University \\ KATIE KNUTSON \\ Public Consulting Group
}

\begin{abstract}
Previous studies, both international and domestic, rarely examined racial disparities in post-release employment and recidivism. Finding a job is an immediate challenge to all ex-prisoners, and often more difficult for African American ex-prisoners who typically return to economically-depressed neighborhoods upon release from prison. The present researchers conducted a 5-year (2005-2009) follow-up study in an attempt to understand racial disparities in post-release employment and recidivism among 6,394 ex-prisoners $(2,531$ Caucasian ex-prisoners and 3,863 African American ex-prisoners), while controlling for the ex-prisoner's level of education. Results of this study showed that African American ex-prisoners had a higher unemployment rate and recidivism rate than Caucasian ex-prisoners. This study also revealed that ex-prisoners, if employed, would likely be under-employed and experience difficulties in sustaining employment, regardless of the ex-prisoner's race. Most importantly, post-release employment and level of education were the two most influential predictors to recidivism among ex-prisoners, regardless of race.
\end{abstract}

Keywords: Prison Education; Reentry; Racial Disparities; Employment; Sociology

\section{Introduction}

Quite often, post-release employment is regarded as the most influential factor in determining recidivism, but rarely have researchers obtained post-release employment data to further analyze the effect of post-release employment on recidivism among ex-prisoners. Ex-prisoners are usually characterized as economically poor, educationally illiterate, and disproportionally unemployed after release from prison. Researchers (Clear, et al., 2001; Gunnison and Helfgott, 2010; Lukies, et al., 2011) indicated that employers were reluctant to hire ex-prisoners. Additionally, ex-prisoners generally lacked up-to-date job skills or formal education to meet the job demands from a variety of industrial sectors (Lockwood, et al., 2012; Nally, et al., 2012).

It is reasonable to believe that uneducated and unskilled ex-prisoners are likely to be unemployed after release from prison; and, probably that they will become recidivists simply because they do not have the financial means for independent living in the community. To examine the interrelationship between an ex-prisoner's education, post-release employment, and recidivism, the present researchers collected both post-released employment and recidivism-related information to conduct a 5-year follow-up study of a cohort of 6,394 ex-prisoners from the Indiana Department of Correction (IDOC). There has been very little research on racial disparities in post-release employment and recidivism, while considering an ex-prisoner's level of education. Additionally, this study explored the role of an ex-prisoner's level of education in determining post-release employment and recidivism.

Previous studies of post-release recidivism identified a variety of factors, such as educational illiteracy, lack of job skills, lack of interpersonal skills, criminal history, or unemployment, as contributors to a relatively high recidivism rate among ex-prisoners (Hemphill et al., 1998; Kubrin and Stewart, 2006; Rossman and Ro- 
man, 2003; Uggen, 2000; Vacca, 2004; Visher et al., 2005). For example, ex-prisoners' criminal records become a barrier to employment because employers are generally reluctant to hire them (Backman, 2011; Clear, et al., 2001; Giguere and Dundes, 2002; Gunnison and Helfgott, 2010; Harris and Keller, 2005; Lukies, et al., 2011; Varghese, et al., 2010). Furthermore, Nally, et al., (2014(a); 2012) found that a notable number of ex-prisoners lacked formal education and job training during incarceration, which resulted in a relatively high unemployment rate among ex-prisoners after release from prison. Nonetheless, consistent findings from previous studies indicated post-release employment and recidivism among ex-prisoners were empirically correlated (Allen, 1988; Blomberg, et al., 2012; Burke and Vivian, 2001; Vacca, 2004; Wilson, et al., 2000).

\section{Racial Disparities in Post-Release Recidivism}

Identifying racial disparities in post-release recidivism, undoubtedly, is very complex and difficult to measure. Researchers (Hipp and Yates, 2009; Kubrin and Stewart, 2006; Olusanya and Gau, 2012; Reisig, et al., 2007) frequently used the neighborhood context to explain racial disparities in recidivism. Accordingly, African American ex-prisoners would likely have a higher recidivism rate than Caucasian ex-prisoners because they would often return to neighborhoods saturated with poverty, high unemployment, and crime. It is important to note that, due to a relatively small sample or lack of race-specific coding, this study only included Caucasian and African American ex-prisoners.

However, a neighborhood-based contextual analysis of post-release recidivism could be misleading, not accounting for the underlying problems of socio-economic disadvantages in African American neighborhoods. For example, there are substantially fewer business establishments in predominately African American neighborhoods to provide job opportunities to African American ex-prisoners. To fully understand racial disparities in post-release employment and recidivism, this study used an individual-level analysis across ex-prisoners' characteristics (demographic or employment status) as indicators for post-release recidivism among ex-prisoners with different ethnicities. In other words, a systematic collection of post-release employment information among ex-prisoners after release from prison was used in an attempt to examine any empirical correlation between post-release employment and recidivism, while controlling for an ex-prisoner's race. In doing so, racial disparities or similarities in post-release employment and recidivism were identified clearly.

\section{Educational Gaps among Incarcerated Ex-prisoners}

According to the recent school drop-out rates from the National Center for Education Statistics (U.S. Department of Education, 2012), the school drop-out rate in 2010, in the age group of 16-24 years old, was 8.0 percent among African Americans, but only 5.1 percent among Caucasians. Even though the gap between Caucasians and African Americans has narrowed in the past decade, school drop-outs among African American teens are high. On the other hand, prisoner statistics from the U.S Department of Justice (2012) showed that more than 40 percent of prison inmates (as of June 30, 2009) were African American, which represented 4.8 percent per 100,000 African American males.

In the criminology arena, education is generally perceived as a deterrent to crime. Previous studies (Chappell, 2002; Erisman and Contardo, 2005; Steurer and Smith, 2003; Winterfield, et al., 2009) indicated that ex-prisoners with lower levels of formal education were disproportionally unemployed after release from prison. However, the effect of an ex-prisoner's level of education on post-release recidivism would need to be examined further.

Nally, et al. (2014(a), 2012) indicated that ex-prisoners who lacked educational competency or job skills were likely to have a higher unemployment rate and recidivism rate after release from prison. Educational deficiency, undoubtedly, is a common problem among incarcerated inmates. Even though most adult correctional facilities have provided educational programs, such as basic literacy and high school equivalency classes, correctional education administrators are struggling to accommodate an increasing demand for academic remedies for educationally-deficient inmates. Quite often, inmates cannot complete education program requirements due to early release or administrative transfers from one prison to another. Another serious challenge was that funding for correctional education programs across the nation was reduced because of shrinking state budgets and weak economic conditions. As a result, ex-prisoners lacked the competencies to meet job demands from most employment sectors upon release from prison. The present researchers examined the impact of an ex-prisoner's level of education on post-release employment and recidivism, and also systematically analyzed racial disparities relative to post-release employment and recidivism. 
Barriers to Post-Release Employment among Ex-prisoners

According to recent employment statistics (U.S. Department of Labor, 2012), the African-American unemployment rate surged to 14.4 percent in June of 2012; however, it was only 7.4 percent for Caucasians. For young African American males, the unemployment rate was much higher. And, recent prison statistics from the Bureau of Justice Statistics (U.S. Department of Justice, 2012) indicated that African American non-Hispanic males, at year-end 2010, had an imprisonment rate $(3,074$ per 100,000 U.S. African American male residents) that was nearly 7 times higher than Caucasian non-Hispanic males (459 per 100,000 U.S. Caucasian male residents). Furthermore, an estimated 7.3 percent of African American males ages 30-34 were in state or federal prison in 2010.

Undoubtedly, ex-prisoners would encounter incremental challenges to finding jobs when they were released from prison. Results from previous studies (Bellair and Kowalski, 2011; Cox, 2010; Wang, et al., 2010) indicated that economic conditions (e.g., recession) exerted a great impact on post-release employment and recidivism among ex-prisoners. However, the effect of economic circumstances on post-release recidivism was difficult to verify because previous studies lacked specific, individual-based employment information among ex-prisoners. A recent study (Nally, et al., 2011) revealed the unemployment rate among ex-prisoners was 65.6 percent during the recent recessionary period of 2008-2009, which was 10 times higher than the general population. Such findings clearly show that ex-prisoners encounter numerous hardships in obtaining a job upon release from prison. These hardships are not limited to criminal backgrounds or educational competency but also the economic conditions at the time of release to their communities. It is important to mention that the present researchers collected the employment-related information of ex-prisoners who were employed after release from prison. This 5-year follow-up study carefully analyzed racial disparities in post-release employment rates before, during, and after the recent economic recession of 2008. In doing so, any distinctive effect of economic conditions on post-release employment among different races was determined.

\section{Data Description}

\section{Methodology}

The present researchers conducted a 5-year (20052009) follow-up study on the correlation between post-release recidivism and employment, while con- trolling for an ex-prisoner's level of education, among a cohort of 6,561 ex-prisoners who were released to five Indiana metropolitan counties from the Indiana Department of Correction (IDOC) throughout 2005. One main focus in this study was to examine racial disparities (or similarities) in post-release recidivism and employment among ex-prisoners with a different level of education prior to release from prison. In order to deliberately examine racial disparities (African American versus Caucasian ex-prisoners) in post-release employment and recidivism, approximately 2.5 percent $(n=167)$ of ex-prisoners who were Hispanic, Asian, or other ethnicities were excluded from the present analyses. Therefore, the sample in this study included 2,531 Caucasian and 3,863 African American ex-prisoners, totaling 6,394 ex-prisoners who were released from IDOC throughout 2005.

The dataset of the present study was collected from three (3) primary data sources: (1) IDOC Division of Research and Planning, (2) IDOC Education Division, and (3) Indiana Department of Workforce Development (IDWD). The IDOC Division of Research and Planning provided up-to-date information such as ex-prisoners' demographical characteristics and legal information (e.g., re-conviction or re-admission to Indiana prison). The IDOC Education Division provided the incarcerated ex-prisoners' level of education prior (e.g. high school completion) to release from IDOC custody. The IDWD verified the ex-prisoner's post-release employment information (e.g., job title or income), if employed. The IDWD documented employment information quarterly, but there would be no employment information among ex-prisoners if they had never been employed since release from prison during the study period. The IDWD data also included quarterly income, which would indicate the length of employment and annual income among ex-prisoners if they were employed during the study period of 2005-2009. Meanwhile, the IDWD systematically documented the job sectors where ex-prisoners were employed. Previous studies on post-release recidivism usually lacked post-release employment data that limited the understanding of the impact of employment on recidivism.

\section{Outcome Measures}

Racial disparities and/or similarities in post-release recidivism and employment were two major outcome measures in this 5-year follow-up study. It is important to mention that this 5-year follow-up study was conducted during the timeframe of the recent economic recession which started in December of 2007 and ended in December of 2008 (U.S. Department of La- 
bor, 2012). Accordingly, this 5-year follow-up study (2005-2009) would examine the post-release unemployment rates among Caucasian and African American ex-prisoners in the pre-recessionary, during-recessionary, and post-recessionary period. Meanwhile, the present researchers would further analyze racial disparities in the length of employment and annual income between Caucasian and African American ex-prisoners. Undoubtedly, the correlation between post-release recidivism and employment would be the main focus in this study. Additionally, the contributing factors to post-release recidivism were examined among all Indiana ex-prisoners, Caucasian ex-prisoners, and African American ex-prisoners.

In this study, post-release recidivism was measured by re-incarceration in the Indiana Department of Correction, which would include a violation of parole (including technical and regular), violation of probation (including technical and regular), committing a new crime, or a violation of community transition program (similar to probation and parole). Through reviewing IDOC data, such as ex-prisoners' release dates and return dates, the present researchers could determine the recidivism status of the ex-prisoner. Also, the survival time (elapsed time between release and return to IDOC custody) among recidivist ex-prisoners was calculated. By calculating the elapsed time between the date of re-incarceration and the initial release, the present researchers could examine racial disparities (or similarities) in the patterns of re-incarceration (i.e., recidivism) between Caucasian and African American recidivist ex-prisoners in the study period of 2005-2009. Such information would allow the present researchers to examine whether or not African American or Caucasian ex-prisoners were likely to become recidivist ex-prisoners and contributing factors to post-release recidivism among each ethnic group. However, due to limitations of data, the present study could not analyze some important effects, such as drug treatment programs, housing, or relationships with the family, on post-release recidivism.

\section{Data Analysis}

Data analyses in this study included characteristics (i.e., race, gender, age, and education) relative to post-release recidivism and employment among 6,394 ex-prisoners who were released to five metropolitan counties from the Indiana Department of Correction (IDOC) throughout 2005. One specific focus of the data analysis was racial disparities and/or similarities in post-release recidivism and employment between Caucasian and African American ex-prisoners, while controlling for the ex-prisoner's level of education. By using data from IDWD, the present researchers were able to examine the unemployment rate among Caucasian and African American ex-prisoners. Rarely had researchers examined the income that ex-prisoners could earn, if employed, after release from prison. With the IDWD data, the present researchers could examine the earnings and the length of employment among employed, ex-prisoners. In the meantime, racial disparities and/or similarities in the unemployment rate, length of employment, and annual income between Caucasian and African American employed ex-prisoners were carefully examined.

One main analysis in this study was to further examine post-release recidivism and employment among Caucasian and African American ex-prisoners with a different level of education (i.e., below high school, high school, and college). Such analyses allowed the present researchers to examine the effect of an ex-prisoner's level of education on post-release recidivism and employment. Meanwhile, the effects of ex-prisoner's characteristics (e.g., race or age) and post-release employment on recidivism were carefully examined in order to understand the patterns of racial disparities (or similarities) in determining the post-release recidivism between Caucasian and African American ex-prisoners. Also in this study, the patterns of re-incarceration between Caucasian and African American ex-prisoners, with a different level of education, were examined. Due to the dichotomous nature of dependent measurement (recidivist ex-prisoners versus non-recidivist ex-prisoners), a logistic multiple regression analysis was used to examine the effect of ex-prisoners' characteristics and post-release employment on recidivism in three different samples (all ex-prisoners, Caucasian ex-prisoners, and African American ex-prisoners). These multiple regression analyses provided a clear indication of which of the ex-prisoner's characteristics had exerted the most influential impact on post-release recidivism among Caucasian and African American ex-prisoners.

\section{Findings}

Table 1 illustrates the ex-prisoner's demographical characteristics, education, post-release employment, and recidivism status. Results of this 5-year follow-up study of 6,394 ex-prisoners showed that a majority of ex-prisoners were male, in the age range of 20-40 years old. Specifically, 86.5 percent $(n=5,529)$ of ex-prisoners were male and 13.5 percent $(n=865)$ were female. In regard to age, this study's results showed that 1.8 percent $(n=118)$ of 6,394 ex-prisoners were under 20 
years old, 36.0 percent $(n=2,304)$ were in the age range of 20-29 year old, 30.3 percent $(n=1,938)$ were in the age group of 30-39 years old, 24.3 percent $(n=1,556)$ were in the age group of 40-49 years old, 6.4 percent $(n=407)$ were in the age group of 50-59 years old, and 1.1 percent $(n=71)$ were 60 years old or above. Results of this study also revealed that racial disparities in ex-prisoners' gender and age were insignificant.

In terms of ex-prisoners' level of education, this study's results showed that 35.1 percent $(n=2,247)$ of a total of 6,394 ex-prisoners had an education below high school, 53.0 percent $(n=3,391)$ had a high school diploma or equivalent, 4.7 percent $(n=300)$ had completed a 2-year college degree, and 7.1 percent $(n=456)$ had an unknown education level. However, this study's results showed that racial disparities in ex-prisoners' level of education were notable. Even though the IDOC provided access to high school curricula, through high school equivalency instruction and testing in adult correctional facilities, this study found that a notable number of African American ex-prisoners did not complete high school equivalency prior to release from prison. For 2,531 Caucasian ex-prisoners, 29.8 percent $(n=753)$ had an education below high school, 57.2 percent $(n=1,447)$ had a high school diploma or equivalent, 5.7 percent $(\mathrm{n}=145)$ had completed a 2-year college degree, and 7.3 percent $(n=186)$ had an unknown education level. For 3,863 African American ex-prisoners, 38.7 percent $(n=1,494)$ had an education below high school, 50.3 percent $(n=1,944)$ of ex-prisoners had a high school diploma or equivalent, 4.0 percent $(n=155)$ had completed a 2-year college degree, and 7.0 percent $(n=270)$ had an unknown education level.

As Table I indicates, during the study period of 2005 2009 , approximately 62.5 percent $(n=3,998)$ of a total of 6,394 ex-prisoners were employed for at least one

Table 1:Descriptive statistics of ex-prisoners' characteristics $(\mathrm{N}=6,394)$

\begin{tabular}{lccr}
\hline Variable & Caucasian & African American & \multicolumn{1}{c}{ Overall } \\
\hline Ex-prisoner Gender & $(\mathrm{n}=2,531)$ & $(\mathrm{n}=3,863)$ & $(\mathrm{N}=6,394)$ \\
$\quad$ & & & \\
$\quad$ female & $379(15.0 \%)$ & $486(12.6 \%)$ & $865(13.5 \%)$ \\
$\quad$ male & $2152(85.0 \%)$ & $3377(87.4 \%)$ & $5529(86.5 \%)$
\end{tabular}

Ex-prisoner Age

under 20 years old

20-29 years old

30-39 years old

$40-49$ years old

50-59 years old

60 years old or above

Ex-prisoner Education

below high school

high school or GED

college

unknown

Employment Status

unemployed

employed

$$
\begin{gathered}
90(2.3 \%) \\
1434(37.1 \%) \\
1146(29.7 \%) \\
913(23.6 \%) \\
238(6.2 \%) \\
42(1.1 \%)
\end{gathered}
$$

$$
\begin{gathered}
1494(38.7 \%) \\
1944(50.3 \%) \\
155(4.0 \%) \\
270(7.0 \%)
\end{gathered}
$$

$$
\begin{array}{r}
753(29.8 \%) \\
1447(57.2 \%) \\
145(5.7 \%) \\
186(7.3 \%)
\end{array}
$$

$849(33.5 \%)$

$1682(66.5 \%)$

$$
\begin{aligned}
& 1547(40.0 \%) \\
& 2316(60.0 \%)
\end{aligned}
$$

$118(1.8 \%)$
$2304(36.0 \%)$
$1938(30.3 \%)$
$1556(24.3 \%)$
$407(6.4 \%)$
$71(1.1 \%)$

2247 (35.1\%)

$3391(53.0 \%)$

$300(4.7 \%)$

$456(7.1 \%)$

Recidivism Status

$\begin{array}{llll}\text { non-recidivist ex-prisoner } & 1396(55.2 \%) & 1910(49.4 \%) & 3306(51.7 \%) \\ \text { recidivist ex-prisoner } & 1135(44.8 \%) & 1953(50.6 \%) & 3088(48.3 \%)\end{array}$

Note: The released ex-prisoner was regarded as "employed," if he or she was employed at least one quarter in any given year in the study period. On the other hand, the released ex-prisoner was regarded as "unemployed," if he or she had never been employed since release from IDOC custody in 2005. 
quarter after release from prison. The post-release recidivism rate among 6,396 ex-prisoners in this 5-year follow-up period reached as high as 48.3 percent. This study also indicated that racial disparities in post-release employment and recidivism were distinguishable. Results of this study revealed that African American ex-prisoners, rather than Caucasian ex-prisoners, would likely be unemployed after release from prison. Specifically, 40.0 percent $(n=1,547)$ of 3,863 African American ex-prisoners, but only 33.5 percent $(n=849)$ of 2,531 Caucasian ex-prisoners, were never employed after release from prison. Most importantly, this study found that the recidivism rate among 3,863 African American ex-prisoners was 50.6 percent, but only 44.8 percent among 2,531 Caucasian ex-prisoners.

Table 2 illustrates the unemployment rates among 6,394 ex-prisoners, including 2,531 Caucasian ex-pris- oners, and 3,863 African American ex-prisoners during the study period of 2005-2009.

Based upon IDWD employment information among ex-prisoners, results of this study revealed that ex-prisoners had encountered tremendous difficulties in finding jobs upon release from prison. This study's results clearly showed that regardless of race, ex-prisoners were virtually unemployed within the first year $\left(1^{\text {st }}\right.$ quarter thru $4^{\text {th }}$ quarter) after the initial release from prison. Specifically, the unemployment rates among both Caucasian and African American ex-prisoners were in the range of 92-97 percent from $1^{\text {st }}$ quarter to $4^{\text {th }}$ quarter in 2005. This study's results also revealed that African American ex-prisoners had consistently higher unemployment rates than Caucasian ex-prisoners throughout the study period of 2005-2009, but such differences might seem to be insignificant.

Table 2: $\quad$ Racial disparities in the unemployment rates after the initial release in 2005 (Excluding ex-prisoners were incarcerated in that given time period)

\begin{tabular}{|c|c|c|c|}
\hline Time Period & Caucasian & African American & Overall \\
\hline $20051^{\text {st }}$ Ouarter & $\frac{(\mathrm{n}=2,531)}{966^{6}}$ & $\frac{(\mathrm{n}=3,863)}{06,06}$ & $(\mathrm{~N}=6,394)$ \\
\hline $20052^{\text {nd }}$ Ouarter & $0580 /$ & $055 \%$ & $056 \%$ \\
\hline $20053^{\text {rd }}$ Quarter & $93.7 \%$ & $93.4 \%$ & $93.5 \%$ \\
\hline $20054^{\text {th }}$ Quarter & $93.1 \%$ & $92.4 \%$ & $92.7 \%$ \\
\hline $20061^{\text {st }}$ Quarter & $59.5 \%$ & $65.3 \%$ & $63.0 \%$ \\
\hline $20062^{\text {nd }}$ Quarter & $58.3 \%$ & $63.9 \%$ & $61.6 \%$ \\
\hline $20063^{\text {rd }}$ Quarter & $59.4 \%$ & $63.2 \%$ & $61.7 \%$ \\
\hline $20064^{\text {th }}$ Quarter & $61.9 \%$ & $64.8 \%$ & $63.7 \%$ \\
\hline $20071^{\text {st }}$ Quarter & $65.9 \%$ & $72.2 \%$ & $69.7 \%$ \\
\hline $20072^{\text {nd }}$ Quarter & $65.1 \%$ & $71.9 \%$ & $69.1 \%$ \\
\hline $20073^{\text {rd }}$ Quarter & $64.9 \%$ & $69.0 \%$ & $67.3 \%$ \\
\hline $20074^{\text {th }}$ Quarter & $66.9 \%$ & $71.6 \%$ & $69.7 \%$ \\
\hline $20081^{\text {st }}$ Quarter & $70.3 \%$ & $76.2 \%$ & $73.8 \%$ \\
\hline $20082^{\text {nd }}$ Quarter & $69.4 \%$ & $75.9 \%$ & $73.3 \%$ \\
\hline $20083^{\text {rd }}$ Quarter & $72.2 \%$ & $75.6 \%$ & $74.2 \%$ \\
\hline $20084^{\text {th }}$ Quarter & $74.7 \%$ & $77.8 \%$ & $76.5 \%$ \\
\hline $20091^{\text {st }}$ Quarter & $78.4 \%$ & $82.3 \%$ & $80.7 \%$ \\
\hline $20092^{\text {nd }}$ Quarter & $77.0 \%$ & $82.4 \%$ & $80.2 \%$ \\
\hline $20093^{\text {rd }}$ Quarter & $78.8 \%$ & $82.8 \%$ & $81.2 \%$ \\
\hline $20094^{\text {th }}$ Quarter & $76.7 \%$ & $79.3 \%$ & $78.2 \%$ \\
\hline
\end{tabular}


As Table 2 indicates, this study's results also revealed that post-release employment among Indiana ex-prisoners improved slowly and steadily from 2005-2009. For example, the unemployment rates steadily decreased from the range of 90 percent (from $1^{\text {st }}$ quarter to $4^{\text {th }}$ quarter of 2005) to the range of 60 percent during the pre-recession period (from $1^{\text {st }}$ quarter of 2006 to $3^{\text {rd }}$ quarter of 2007). It also indicated that ex-prisoners had a better chance of finding employment during strong economic conditions, but the unemployment rates among ex-prisoners remained higher than the general population. Expectedly, the unemployment rates increased into the range of 70 percent during the recession period (from $4^{\text {th }}$ quarter of 2007 to $4^{\text {th }}$ quarter of 2008) and became even higher during the post-recession period (from $1^{\text {st }}$ quarter of 2009 to $4^{\text {th }}$ quarter of 2009). In this 5-year study, there was a similar pattern of unemployment among Caucasian ex-prisoners and African American ex-prisoners during the pre-recession period, the recession period, and the post-recession period.

Even though there was a relatively high unemployment rate among ex-prisoners in the study period of 2005-2009, the analysis revealed that approximately

Table 3: $\quad$ Racial disparities in Length of Employment (by quarter) among employed ex-prisoners in the study period of 2005-2009

\begin{tabular}{|c|c|c|c|}
\hline Number of Quarter & Caucasian & African American & Overall \\
\hline & $(n=1,682)$ & $(\mathrm{n}=2,316)$ & $(\mathrm{N}=3,998)$ \\
\hline Had 1 quarter of employment & $219(13.0 \%)$ & $357(15.4 \%)$ & $576(14.4 \%)$ \\
\hline Had 2 quarters of employment & $218(13.0 \%)$ & $307(13.3 \%)$ & $525(13.1 \%)$ \\
\hline Had 3 quarter of employment & $161(9.6 \%)$ & $243(10.5 \%)$ & $404(10.1 \%)$ \\
\hline Had 4 quarters of employment & $136(8.1 \%)$ & $200(8.6 \%)$ & $336(8.4 \%)$ \\
\hline Had 5 quarter of employment & $124(7.4 \%)$ & $152(6.6 \%)$ & $276(6.9 \%)$ \\
\hline Had 6 quarters of employment & $98(5.8 \%)$ & $157(6.8 \%)$ & $255(6.4 \%)$ \\
\hline Had 7 quarter of employment & $84(5.0 \%)$ & $132(5.7 \%)$ & $216(5.4 \%)$ \\
\hline Had 8 quarters of employment & $81(4.8 \%)$ & $115(5.0 \%)$ & $196(4.9 \%)$ \\
\hline Had 9 quarter of employment & $78(4.6 \%)$ & $107(4.6 \%)$ & $185(4.6 \%)$ \\
\hline Had 10 quarters of employment & $77(4.6 \%)$ & $82(3.5 \%)$ & $159(4.0 \%)$ \\
\hline Had 11 quarter of employment & $63(3.7 \%)$ & $84(3.6 \%)$ & $147(3.7 \%)$ \\
\hline Had 12 quarters of employment & $60(3.6 \%)$ & $83(3.6 \%)$ & $143(3.6 \%)$ \\
\hline Had 13 quarter of employment & $62(3.7 \%)$ & $58(2.5 \%)$ & $120(3.0 \%)$ \\
\hline Had 14 quarters of employment & $60(3.6 \%)$ & $51(2.2 \%)$ & $111(2.8 \%)$ \\
\hline Had 15 quarter of employment & $46(2.7 \%)$ & $51(2.2 \%)$ & $97(2.4 \%)$ \\
\hline Had 16 quarters of employment & $89(5.3 \%)$ & $101(4.4 \%)$ & $190(4.8 \%)$ \\
\hline Had 17 quarter of employment & $16(1.0 \%)$ & $13(0.6 \%)$ & $29(0.7 \%)$ \\
\hline Had 18 quarters of employment & $8(0.5 \%)$ & $14(0.6 \%)$ & $22(0.6 \%)$ \\
\hline Had 19 quarter of employment & $1(0.1 \%)$ & $9(0.4 \%)$ & $10(0.3 \%)$ \\
\hline Had 20 quarters of employment & $1(0.1 \%)$ & $0(0.0 \%)$ & $1(0.0 \%)$ \\
\hline
\end{tabular}


62.5 percent $(n=3,998)$ of a total of 6,394 ex-prisoners had been employed for at least one quarter after release from prison. Table 3 illustrates the length of employment among 3,998 employed ex-prisoners, which included 1,682 Caucasian ex-prisoners and 2,316 African American ex-prisoners. Additionally, results of this study showed that regardless of race, ex-prisoners, if employed, would likely be under-employed and experience difficulties in sustaining employment. For example, in the study period of 2005-2009, approximately 46.0 percent of 3,998 employed ex-prisoners had 1-4 quarters of employment after release from prison, 14.4 percent ( $\mathrm{n}=576)$ had only 1 quarter of employment, 13.1 percent $(n=525)$ had 2 quarters of employment, 10.1 percent $(n=404)$ had 3 quarters of employment, and 8.4 percent $(n=336)$ had 4 quarters of employment. Meanwhile, almost 70 percent of employed ex-prisoners had less than 12 quarters (i.e., 2 years) of employment in this 5-year follow-up study. These statistics regarding length of employment indicated that ex-prisoners were likely employed as part-time workers, but were less likely to retain their employment for an extended time period.

Statistics regarding length of employment, as Table 3 indicates, showed that racial disparities in the length of employment were not significant. Regardless of
American ex-prisoners, had been employed 1-4 quarters after release from prison. Relatively few ex-prisoners, if employed, retained their employment more than 8 quarters (i.e., 2 years), regardless of race or type of employment.

With assistance from IDWD, the present researchers were able to systematically collect and analyze the earnings among employed ex-prisoners. As Table 4 illustrates, results of this study revealed that a majority of ex-prisoners, both Caucasian and African American, would likely earn a low wage if employed. Most surprisingly, there were a significant number of employed ex-prisoners, both Caucasian and African American, who earned less than 5,000 dollars annually in the study period of 2005-2009. Regardless of ex-prisoner race, this study also found that ex-prisoners, if employed, were likely to be marginally-employed. Most marginally-employed ex-prisoners were only employed 1-2 quarters in any given year during this 5-year study period. Consequently, such marginally-employed ex-prisoners were likely to be classified as "working poor" and their annual income was clearly under the poverty line.

One striking finding in this study was that racial disparities in earnings among employed ex-prisoners were significant. Specifically, African American ex-prison-

Table 4: $\quad$ Racial disparities in annual income among employed ex-prisoners in the study period of 2005-2009 (statistics in percentage)

\begin{tabular}{|c|c|c|c|c|c|c|c|c|c|c|}
\hline \multirow[t]{2}{*}{ Income Level/Year } & \multicolumn{2}{|c|}{2005} & \multicolumn{2}{|c|}{2006} & \multicolumn{2}{|c|}{2007} & \multicolumn{2}{|c|}{2008} & \multicolumn{2}{|c|}{2009} \\
\hline & $\mathrm{W}$ & B & $\mathrm{W}$ & $\mathrm{B}$ & $\mathrm{W}$ & B & $\mathrm{W}$ & $\mathrm{B}$ & $\mathrm{W}$ & $\mathrm{B}$ \\
\hline Under $\$ 5,000$ & 41.3 & 55.0 & 41.0 & 53.3 & 41.3 & 52.9 & 43.8 & 54.8 & 45.1 & 53.9 \\
\hline Between $\$ 5,000-\$ 9,999$ & 21.6 & 31.1 & 18.4 & 18.2 & 17.6 & 17.8 & 16.1 & 15.7 & 17.1 & 17.9 \\
\hline Between $\$ 10,000-\$ 19,999$ & 26.9 & 11.3 & 22.4 & 19.7 & 20.7 & 18.2 & 19.6 & 15.7 & 18.5 & 14.3 \\
\hline Between $\$ 20,000-\$ 29,999$ & 7.2 & 2.1 & 10.4 & 5.7 & 11.9 & 7.1 & 11.7 & 8.0 & 9.7 & 7.9 \\
\hline Between $\$ 30,000-\$ 39,999$ & 2.4 & 0.0 & 4.8 & 1.8 & 5.2 & 2.7 & 5.5 & 4.0 & 6.0 & 3.7 \\
\hline$\$ 40,000$ or above & 0.6 & 0.4 & 2.9 & 1.1 & 3.3 & 1.3 & 3.4 & 1.7 & 3.7 & 2.3 \\
\hline
\end{tabular}

Note: "W" represents for Caucasian ex-prisoners and "B" for African American ex-prisoners

ex-prisoner race, a majority of ex-prisoners, if employed, would likely have 1-4 quarters of employment in a variety of industrial sectors after release from prison. For example, 43.7 percent of 1,682 employed Caucasian ex-prisoners, and 47.8 percent of 2,316 African ers consistently earned less than Caucasian ex-prisoners, if employed. For example, as Table 4 indicates, there were more African American ex-prisoners than Caucasian ex-prisoners with an annual income below 5,000 dollars in any given year during the study pe- 
riod of 2005-2009 (i.e., 55.0\% versus $41.3 \%$ in 2005 ; $53.3 \%$ versus $41.0 \%$ in $2006 ; 52.9 \%$ versus $41.3 \%$ in $2007 ; 54.8 \%$ versus $43.8 \%$ in $2008 ; 53.9 \%$ versus $45.1 \%$ in 2009). The study demonstrated a similar pattern across all income levels in regard to racial disparities in annual income among employed ex-prisoners. This disparity in income between African American and Caucasian "employed" ex-prisoners was persistent throughout the pre-recession, recession, and post-recession period. This study also found that a relatively small number of employed ex-prisoners, regardless of race, earned 20,000 dollars or more in any given year of the study period.

As Table 5 illustrates, the present researchers also examined racial disparities in re-incarceration in terms of survival time (i.e., elapsed time between the initial release and re-incarceration) among 3,086 recidivist ex-prisoners, which included 1,134 Caucasian ex-prisoners and 1,952 African American ex-prisoners. The most striking finding was that a notable number of ex-prisoners were likely to be re-incarcerated within 12 months (i.e., 1 year) after the initial release from prison, regardless of ex-prisoner race. Specifically, results of this study revealed that 46.7 percent $(n=1,439)$

Table 5: Racial disparities in elapsed time of re-incarceration after the Initial Release among recidivist ex-prisoners

\begin{tabular}{|c|c|c|c|}
\hline Time Return & Caucasian & African American & Overall \\
\hline & $(\mathrm{n}=1,134)$ & $(n=1,952)$ & $(\mathrm{N}=3,086)$ \\
\hline Within 3 months & $65(5.7 \%)$ & $132(6.8 \%)$ & $197(6.4 \%)$ \\
\hline Within 3-6 months & $143(12.6 \%)$ & $254(13.0 \%)$ & $397(12.9 \%)$ \\
\hline Within 6-9 months & $175(15.4 \%)$ & $265(13.6 \%)$ & $440(14.3 \%)$ \\
\hline Within 9-12 months & $152(13.4 \%)$ & $253(13.0 \%)$ & $405(13.1 \%)$ \\
\hline Within $12-15$ months & $127(11.2 \%)$ & $215(11.0 \%)$ & $342(11.1 \%)$ \\
\hline Within $15-18$ months & $124(10.9 \%)$ & $173(8.9 \%)$ & $297(9.6 \%)$ \\
\hline Within 18-21 months & $81(7.1 \%)$ & $158(8.1 \%)$ & $239(7.7 \%)$ \\
\hline Within 21-24 months & $66(5.8 \%)$ & $116(5.9 \%)$ & $182(5.9 \%)$ \\
\hline Within 24-27 months & $45(4.0 \%)$ & $108(5.5 \%)$ & $153(5.0 \%)$ \\
\hline Within 27-30 months & $33(2.9 \%)$ & $56(2.9 \%)$ & $89(2.9 \%)$ \\
\hline Within $30-33$ months & $12(1.1 \%)$ & $34(1.7 \%)$ & $46(1.5 \%)$ \\
\hline Within 33-36 months & $2(0.2 \%)$ & $9(0.5 \%)$ & $11(0.4 \%)$ \\
\hline Within 36-39 months & $6(0.5 \%)$ & $5(0.3 \%)$ & $11(0.4 \%)$ \\
\hline Within $39-42$ months & $8(0.7 \%)$ & $23(1.2 \%)$ & $31(1.0 \%)$ \\
\hline Within 42-45 months & $25(2.2 \%)$ & $33(1.7 \%)$ & $58(1.9 \%)$ \\
\hline Within 45-48 months & $22(1.9 \%)$ & $33(1.7 \%)$ & $55(1.8 \%)$ \\
\hline Within 48-51 months & $25(2.2 \%)$ & $39(2.0 \%)$ & $64(2.1 \%)$ \\
\hline Within 51-54 months & $16(1.4 \%)$ & $28(1.4 \%)$ & $44(1.4 \%)$ \\
\hline Within 54-57 months & $5(0.4 \%)$ & $15(0.8 \%)$ & $20(0.6 \%)$ \\
\hline Within 57-60 months & $2(0.2 \%)$ & $3(0.2 \%)$ & $5(0.2 \%)$ \\
\hline
\end{tabular}


of a total of 3,086 recidivist ex-prisoners were re-incarcerated within the first year of release; 6.4 percent $(\mathrm{n}=197)$ were re-incarcerated within 3 months after release, 12.9 percent $(n=397)$ were re-incarcerated within 3-6 months after release, 14.3 percent $(n=440)$ were re-incarcerated within 6-9 months after release, and 13.1 percent $(n=405)$ were re-incarcerated within 9-12 months after release. Furthermore, 81.0 percent $(n=2,499)$ of 3,086 recidivist ex-prisoners were re-incarcerated within 2 years after the initial release from Indiana Department of Correction. This study also found that a vast majority of recidivist ex-prisoners were unemployed.

Results of this study also showed a similar pattern of re-incarceration between Caucasian and African American ex-prisoners, as Table 5 illustrates. Variations in the survival time between Caucasian and African American ex-prisoners were not significant. Specifically, 46.4 percent $(n=904)$ of 1,952 recidivist African American ex-prisoners were re-incarcerated within 12 months (i.e., 1 year); 80.3 percent $(n=1,566)$ of African American ex-prisoners were re-incarcerated within 24 months (i.e., 2 years); 90.9 percent $(n=1,773)$ of African American ex-prisoners were re-incarcerated with 36 months (i.e., 3 years) after the initial release in 2005 . On the other hand, 47.1 percent $(n=535)$ of 1,134 recidivist Caucasian ex-prisoners were re-incarcerated within 12 months (i.e., 1 year); 82.1 percent ( $\mathrm{n}=933$ ) of Caucasian ex-prisoners were re-incarcerated within 24 months (i.e., 2 years); 90.3 percent $(n=1,025)$ of Caucasian ex-prisoners were re-incarcerated with 36 months (i.e., 3 years) after the initial release in 2005 . Undoubtedly, results of this study indicated that ex-prisoners were likely re-incarcerated within the first year of the initial release, and reentry supports need to be provided to ex-prisoners to help reduce the barriers they encounter soon after release.

The present researchers also examined racial disparities (or similarities) in the re-incarceration rate among ex-prisoners with a different level of education in order to analyze the effect of an ex-prisoner's level of education on post-release recidivism. Results of this study, as Table 6 indicates, showed that ex-prisoners with a lower level of education, regardless of race, had a higher recidivism rate than ex-prisoners who had a higher level of education. For example, this study's results revealed that the recidivism rate within the first year after initial release (i.e., within 9-12 months) was 26.2 percent among Caucasian ex-prisoners who had an education below high school, 20.8 percent among Caucasian ex-prisoners who had a high school diploma or GED, and 13.0 percent among Caucasian ex-pris- oners who had a 2-year college degree or higher. On the other hand, the recidivism rate within the first year after initial release was 26.9 percent among African American ex-prisoners who had an education below high school, 22.1 percent among African American ex-prisoners who had a high school diploma or GED, and 14.2 percent among African American ex-prisoners with a 2-year college degree or higher.

Most importantly, this 5-year follow-up study demonstrated the distinct impact of an ex-prisoner's level of education on post-release recidivism. Regardless of race, ex-prisoners who had an education level below high school had a higher recidivism rate than ex-prisoners with either a high school diploma or college degree. At the end of this 5-year follow-up study (i.e., within 57-60 months), the recidivism rate was 55.2 percent among Caucasian ex-prisoners with an education level below high school, 43.4 percent among Caucasian ex-prisoners with a high school diploma, and 31.7 percent among Caucasian ex-prisoners with a 2-year college degree or higher. There was a similar pattern among African American ex-prisoners in regard to post-release recidivism. The recidivism rate was 57.8 percent among African American ex-prisoners with an education below high school, 48.6 percent among African American ex-prisoners with a high school diploma, and 30.8 percent among African American ex-prisoners with a 2-year college degree or higher.

Table 7 illustrates the logistic multiple regression analyses of post-release recidivism among three (3) different samples: all 6,394 ex-prisoners, 2,531 Caucasian ex-prisoners, and 3,863 African American ex-prisoners. In this study, data were standardized across all three (3) logistical multiple regression analyses. Results of the logistic multiple regression analysis (the Overall equation - Table 7) indicated that ex-prisoner's demographic characteristics (i.e., gender and age) and post-release employment were statistically and correlated $(p<.05)$ with recidivism. In other words, results of this study found that male ex-prisoners or younger ex-prisoners were likely to become recidivist ex-prisoners after release from prison. Meanwhile, results also revealed that an ex-prisoner's level of education and post-release employment were statistically, but negatively, correlated $(\mathrm{p}<.001)$ with recidivism. It indicated that ex-prisoners would likely be re-incarcerated if they were uneducated (or under-educated) or unemployed. Most importantly, results of the multiple regression analysis showed that the effect of race on post-release recidivism was not significant.

In regard to 2,531 Caucasian ex-prisoners, results of the logistic multiple regression analysis (the $\underline{\mathrm{Cauca}-}$ 
Table 6: $\quad$ Racial disparities in re-incarceration rate (cumulative) after initial release among Caucasian and African American ex-prisoners with a different level of education

Time Return Caucasian African American

\begin{tabular}{|c|c|c|c|c|c|c|}
\hline & $\begin{array}{c}\text { Below High } \\
\text { School }\end{array}$ & $\begin{array}{l}\text { High } \\
\text { School }\end{array}$ & College & $\begin{array}{c}\text { Below High } \\
\text { School }\end{array}$ & $\begin{array}{l}\text { High } \\
\text { School }\end{array}$ & College \\
\hline & $(n=753)$ & $(n=1447)$ & $(n=145)$ & $(n=1494)$ & $(n=1944)$ & $(\mathrm{n}=155)$ \\
\hline Within 3 months & $3.7 \%$ & $2.3 \%$ & $1.4 \%$ & $3.7 \%$ & $3.3 \%$ & $2.6 \%$ \\
\hline Within 3-6 months & $9.9 \%$ & $8.2 \%$ & $5.5 \%$ & $11.0 \%$ & $9.8 \%$ & $6.5 \%$ \\
\hline Within 6-9 months & $18.9 \%$ & $14.9 \%$ & $9.6 \%$ & $19.3 \%$ & $15.9 \%$ & $9.7 \%$ \\
\hline Within 9-12 months & $26.2 \%$ & $20.8 \%$ & $13.0 \%$ & $26.9 \%$ & $22.1 \%$ & $14.2 \%$ \\
\hline Within $12-15$ months & $33.0 \%$ & $24.7 \%$ & $19.9 \%$ & $33.9 \%$ & $27.1 \%$ & $17.4 \%$ \\
\hline Within $15-18$ months & $39.4 \%$ & $29.5 \%$ & $21.3 \%$ & $38.5 \%$ & $31.6 \%$ & $20.0 \%$ \\
\hline Within 18-21 months & $43.0 \%$ & $32.6 \%$ & $22.7 \%$ & $43.5 \%$ & $35.2 \%$ & $25.2 \%$ \\
\hline Within 21-24 months & $45.4 \%$ & $35.5 \%$ & $26.1 \%$ & $47.0 \%$ & $38.1 \%$ & $25.8 \%$ \\
\hline Within 24-27 months & $47.9 \%$ & $37.0 \%$ & $28.2 \%$ & $50.5 \%$ & $40.6 \%$ & $27.7 \%$ \\
\hline Within 27-30 months & $49.2 \%$ & $38.5 \%$ & $28.9 \%$ & $52.5 \%$ & $41.8 \%$ & $29.0 \%$ \\
\hline Within $30-33$ months & $49.5 \%$ & $39.2 \%$ & $28.9 \%$ & $53.2 \%$ & $43.3 \%$ & $29.0 \%$ \\
\hline Within 33-36 months & $49.8 \%$ & $39.4 \%$ & $28.9 \%$ & $53.4 \%$ & $43.3 \%$ & $29.0 \%$ \\
\hline Within 36-39 months & $51.1 \%$ & $39.7 \%$ & $29.6 \%$ & $53.5 \%$ & $43.5 \%$ & $29.0 \%$ \\
\hline Within $39-42$ months & $51.4 \%$ & $40.8 \%$ & $30.3 \%$ & $54.2 \%$ & $44.1 \%$ & $29.0 \%$ \\
\hline Within 42-45 months & $51.9 \%$ & $41.8 \%$ & $30.3 \%$ & $54.9 \%$ & $44.9 \%$ & $29.6 \%$ \\
\hline Within 45-48 months & $52.7 \%$ & $42.7 \%$ & $30.3 \%$ & $55.6 \%$ & $46.0 \%$ & $29.6 \%$ \\
\hline Within 48-51 months & $53.9 \%$ & $43.3 \%$ & $30.3 \%$ & $56.3 \%$ & $47.4 \%$ & $30.2 \%$ \\
\hline Within 51-54 months & $54.8 \%$ & $43.4 \%$ & $31.0 \%$ & $57.2 \%$ & $48.1 \%$ & $30.8 \%$ \\
\hline Within 54-57 months & $54.9 \%$ & $43.4 \%$ & $31.7 \%$ & $57.7 \%$ & $48.5 \%$ & $30.8 \%$ \\
\hline Within 57-60 months & $55.2 \%$ & $43.4 \%$ & $31.7 \%$ & $57.8 \%$ & $48.6 \%$ & $30.8 \%$ \\
\hline
\end{tabular}

sian equation - Table 7) showed that ex-prisoner age and education were statistically correlated $(p<.05)$ with post-release recidivism. In other words, this study's results revealed that younger or uneducated (or under-educated) Caucasian ex-prisoners were likely to be recidivists. Meanwhile, results of the multiple regression analysis also demonstrated post-release employment was statistically, but negatively, correlated $(p<.001)$ with recidivism among Caucasian ex-prisoners, while controlling for other variables. In other words, post-re- lease employment was the most important predictor to recidivism among Caucasian ex-prisoners.

Among 3,863 African American ex-prisoners, results of the logistic multiple regression analysis (the African American equation - Table 7) showed ex-prisoner's demographic characteristics (i.e., gender, age and education) and post-release employment were statistically correlated $(p<.001)$ with recidivism. In other words, this study's results revealed that male, younger or uneducated (or under-educated) African American 
Table 7: $\quad$ Logistic multiple regression analyses of the post-release recidivism among

Caucasian ex-prisoners, African American ex-prisoners, and all ex-prisoners

\begin{tabular}{lccc}
\hline Variable & Caucasian & African American & Overall \\
\hline & $(\mathrm{n}=2,531)$ & $(\mathrm{n}=3,863)$ & $(\mathrm{N}=6,394)$ \\
Ex-prisoner Race & $\mathrm{n} / \mathrm{a}$ & $\mathrm{n} / \mathrm{a}$ & -.141 \\
Ex-prisoner Gender & -.094 & $.407^{* * *}$ & $.187^{*}$ \\
Ex-prisoner Age & $-.027^{* * *}$ & $-.014^{* * *}$ & $-.019^{* * *}$ \\
Ex-prisoner Education & $-.377^{* * *}$ & $-.389^{* * *}$ & $-.380^{* * *}$ \\
Employment Status & $-.379^{* * *}$ & $-.378^{* * *}$ & $-.374^{* * *}$ \\
Constant & 1.771 & 1.059 & 1.555 \\
\hline
\end{tabular}

Note \#1: $\quad$ Statistics in Table 7 are logistic regression coefficients and "*" denotes that coefficient is statistically significant at 0.05 level, “**” at 0.01 level, and “***” at 0.001 level.

Note \#2: " $\mathrm{n} / \mathrm{a}$ " means that logistic regression coefficient statistic is not applicable in that equation due to the fact that only one racial group has been considered in the equation.

ex-prisoners were likely to be recidivists. Most importantly, results of the multiple regression analysis showed that post-release employment was statistically, but negatively, correlated with recidivism among African American ex-prisoners, while controlling for other variables. Consistent with results from the sample of Caucasian ex-prisoners, post-release employment was the most important predictor of recidivism among African American ex-prisoners.

\section{Discussion}

One important finding from this 5-year follow-up study of 6,394 ex-prisoners from the IDOC was that ex-prisoner race was not statistically and correlated with post-release recidivism, while controlling for other variables. Meanwhile, results of this study consistently revealed that an ex-prisoner's age, level of education, and post-release employment were the most influential indicators of recidivism. Regardless of ex-prisoner race, ex-prisoners were likely to be re-incarcerated if they were young, uneducated (or under-educated), and unemployed after release from prison. Undoubtedly, these ex-prisoners were likely school drop-outs upon admission to IDOC and did not complete the GED program prior to release from IDOC. Consequently, young and uneducated (or under-educated) ex-prisoners found it difficult to obtain employment upon release from prison. A further examination of post-release recidivism in this 5-year follow-up study revealed a recidivism rate of 68.8 percent among African American ex-prisoners who were under 30 years old, under-educated (below high school), and unemployed after re- lease from IDOC. On the other hand, the recidivism rate reached 65.1 percent among Caucasian ex-prisoners who were under 30 years old, under-educated (below high school), and unemployed after release from IDOC. This study also found that young, uneducated and unemployed ex-prisoners had a high recidivism rate and were likely to return to IDOC custody due to committing a new crime or violating probation or parole.

Another important finding in this 5-year follow-up study was that racial disparities in post-release employment were distinctive. In other words, throughout the study period of 2005-2009, African American ex-prisoners would likely have a higher unemployment rate than Caucasian ex-prisoners after release from prison. A further examination showed that post-release employment and recidivism were statistically and negatively correlated (chi-square $=51.79$ at $p<.001$ ). The recidivism rate was 53.7 percent among ex-prisoners who had never been employed after release from IDOC custody. As results of this 5-year follow-up study indicated, at its core, post-release employment was the most influential factor on post-release recidivism regardless of ex-prisoner race.

It is important to mention that it was extremely difficult for ex-prisoners to find a job upon release from prison, and "unemployment" was positively correlated with recidivism, regardless of ex-prisoner race. Nonetheless, this 5-year follow-up study further revealed that not only "finding a job" was an important factor to reduce recidivism, but "retaining employment" was the most influential factor on recidivism among ex-prison- 
ers. Undoubtedly, this study's results clearly indicated that ex-prisoners encountered tremendous difficulties in finding jobs after release from prison; if employed, they were unlikely to retain their employment for a long period of time. Even though this study's results show there are relationships between employment, education and recidivism, however, it cannot be determined from this data the degree to which education in and of itself leads to higher levels of post-release employment. A further examination of the relationship between ex-prisoner education and post-release employment is needed in future research.

This study revealed that racial disparities in levels of education were also significant. Specifically, there were a notable number of young African American males who did not complete high school prior to admission to the Indiana Department of Correction (IDOC) and prior to release from IDOC. Results of this 5-year follow-up study clearly revealed that the effect of an ex-prisoner's level of education on post-release recidivism and employment was significant. In other words, ex-prisoners with a higher level of education would likely have a higher employment rate and a lower recidivism rate compared to those ex-prisoners with a lower level of education. For example, a further examination revealed that the recidivism rate was 61.8 percent among African American male ex-prisoners who were under the age of 30 and without a high school diploma. Those African American male ex-prisoners under the age of 30 with a 2-year college degree or higher had a recidivism rate of 25.9 percent. There was a similar trend among Caucasian ex-prisoners; the recidivism rate decreased when the ex-prisoner's level of education increased.

Most importantly, this 5-year follow-up study clearly revealed that regardless of ex-prisoner race, there was a strong interrelationship between an ex-prisoner's level of education and post-release employment and recidivism. Consistent with previous studies (D'Alessio, et al., 2013; Nally, et al., 2011 \& 2104(a); Phillip and Land, 2012; Varghese, et al., 2010), post-release employment was the most influential factor to determine recidivism among ex-prisoners.

A recent study (Nally, et al., 2012) found that a significant number of incarcerated inmates did not complete high school prior to release from prison and did not possess adequate and up-to-date job skills to meet with demands from a variety of industrial sectors. Consistent with previous researchers' findings (Chappell, 2004; Erisman and Contardo, 2005; Steurer and Smith, 2003), this study found that educationally-illit- erate ex-prisoners were disproportionally unemployed and would likely have a higher recidivism rate. Furthermore, the U.S. Department of Education (2012) indicated that the school drop-out rate in 2010 in the age group of 16-24 years old was 8.0 percent among African Americans, but only 5.1 percent among Caucasians. Racial disparities in educational deficiency further exacerbated many different social problems in urban communities where a majority of ex-prisoners would likely reside after release from prison (U.S. Department of Justice, 1998).

A further examination revealed that 60.5 percent $(n=3,869)$ of a total of 6,394 ex-prisoners in this 5-year follow-up study returned to urban neighborhoods in the Indianapolis metropolitan area after release from IDOC custody; 63.5 percent $(n=2,457)$ of 3,869 ex-prisoners in the metropolitan areas were African American. Due to an array of underlying socio-economic problems in urban communities, ex-prisoners, particularly African American ex-prisoners, would likely have a higher recidivism rate because they typically returned to neighborhoods saturated with poverty, unemployment, and crime. Specifically, post-release recidivism was correlated with unemployment among ex-prisoners (Blomberg, et al., 2012; Burke and Vivian, 2001; Cooney, 2012; Finn, 1998; La Vigne, et al., 2008; Makarios, et al., 2010; Steurer and Smith, 2003; Sung and Richter, 2006; Uggen, 2000). Undoubtedly, these unemployed ex-prisoners would exacerbate the crime problems in urban neighborhoods if there were insufficient supporting mechanisms to facilitate their re-entry into these communities. As this study's results showed, the recidivism rate among young, uneducated (or under-educated), unemployed, African American males was close to 70 percent. Clearly there is a need to address this specific demographic group when developing reentry strategies and supports.

\section{Conclusion}

Results of this study clearly implicated the need to enhance correctional education for incarcerated inmates in order to increase their employability after release from prison; which, in turn, would decrease post-release recidivism. The effect of correctional education on post-release employment and recidivism among ex-prisoners is widely recognized (Burke and Vivian, 2001; Nuttall et al., 2003; Rose, et al., 2010; Vacca, 2004). Correctional education plays a crucial role in enhancing the odds for post-release employment which is critical to an ex-prisoner's successful reentry. For many incarcerated ex-prisoners, African American, in 
particular, correctional education might be the only educational remedy for improving their educational competencies and job skills prior to release from prison. Furthermore, correctional education could be a partial solution to narrowing racial disparities in post-release employment and recidivism among ex-prisoners.

A most recent study (Nally, et al., 2014(b)), which exclusively analyzed the job sectors that hired ex-prisoners, found that ex-prisoners likely would be employed in the following five major industrial sectors; they are (ranked in order): (1) the "temporary help services" sector, (2) the "leisure \& hospitality" sector, (3) the "manufacturing" sector, (4) the "construction" sector, and (5) the "retail trade" sector. Nally, et al. (2014(b)) further indicated that the "temporary help services" and "leisure \& hospitality" sectors were the two most prevalent employers of ex-prisoners, providing mostly hourly-based or seasonally labor-intensive jobs. Undoubtedly, skill-based manufacturing or construction jobs provided better wages for ex-prisoners with the necessary skill sets, but these job opportunities decreased during the recession (Nally, et al., 2014).

In recent years, funding for correctional education programs across the United States has decreased due to federal and state budget constraints. Needless to say, many skill-based vocational programs, such as manufacturing, are difficult to implement in prison settings due to the cost. However, correctional education administrators could selectively implement several of these skill-based programs. Undoubtedly, the benefits of employment-oriented, skill-based correctional education outweigh the cost of incarceration. Future research shall focus on the long-term impact of correctional vocational programs on post-release recidivism among ex-prisoners.

\section{References}

Allen, J. (1988). Administering quality education in an adult correctional facility. Community Services Catalyst, 18(4), 28-29.

Backman, C. (2011). Vocabularies of motive among employers conducting criminal background checks. Acta Sociologica, 54(1), 27-44.

doi: http://dx.doi.org/10.1177/0001699310392601

Bellair, P.E., \& Kowalski, B.R. (2011). Low-skill employment opportunity and African-American-White difference in recidivism. Journal of Research in Crime and Delinquency, 48(2), 176-208. doi:http://dx.doi.org/10.1177/0022427810391536

Blomberg, T.G., Bales, W.D., \& Piquero, A.R. (2012). Is educational achievement a turning point for in carcerated delinquents across race and sex? Journal of Youth and Adolescence 41(2), pp. 202-216 doi:http://dx.doi.org/10.1007/s10964-011-9680-4 Burke, L., \& Vivian, J. (2001). The effect of college programming on recidivism rates at the Hampden County House of Correction: A 5-year study. Journal of Correctional Education, 52(4), 160-162.

Chappell, C. (2004). Post-secondary correctional education and recidivism: A meta-analysis of research conducted from 1990-1999. Journal of Correctional Education 55(2), pp. 148-169.

Clear, T.R., Rose, D.R., \& Ryder, J.A. (2001). Incar ceration and the community: The problem of removing and returning offenders. Crime \& Delinquency, 47(3), 335-351. doi:http://dx.doi. org $/ 10.1177 / 0011128701047003003$

Cooney, T.M. (2012). Reducing recidivism through entrepreneurship programmes in prisons. The International Journal of Entrepreneurship and Innovation, 13(2), 125-133.doi: http://dx.doi.org/10.5367/ ijei.2012.0074

Cox, R. (2010). Crime, incarceration, and employment in light of the great recession. The Review of Black Political Economy, 37(3-4), 283-294.doi:http://dx. doi.org/10.1007/s12114-010-9079-6

D’Alessio, S.J., Stolzenberg, L., Eitle, D. (2013). "Last hired, first fired": The effect of the unemployment rate on the probability of repeat offending. American Journal of Criminal Justice, 41(1), 1-17.

Erisman, W., \& Contardo, J.B. (2005). Learning to re duce recidivism: A 50-state analysis of postsecondary correctional education policy. Washington, DC: The Institute for Higher Education Policy.

Giguere, R., \& Dundes, L. (2002). Help wanted: A survey of employer concerns about hiring ex-convicts. Criminal Justice PolicyReview, 13(4), 396-408. doi: http://dx.doi.org/10.1177/088740302237806

Gunnison, E., \& Helfgott, J.B. (2010). Factors that hinder offender reentry success: A view from community corrections officers. International Journal of Offender Therapy and Comparative Criminology, 55(2), 287-304. doi: http://dx.doi. org/10.1177/0306624X09360661

Harris, P.M., \& Keller, K.S. (2005). Ex-offenders need not apply: The criminal background check in hiring decisions. Journal of Contemporary Criminal Justice, 21(1), 6-30. doi: http://dx.doi. org/10.1177/1043986204271678

Hemphill, J.F., Hare, R.D., \& Wong, S. (1998). Psychopathy and recidivism: A review. Legal and Criminological Psychology, 3(1), 139-170.doi: http://dx. 
doi.org/10.1111/j.2044-8333.1998.tb00355.x

Hipp, J.R., \& Yates, D.K. (2009). Do returning parolees affect neighborhood crime? A case study of Sacramento. Criminology, 47(3), 619-656.doi: http:// dx.doi.org/10.1111/j.1745-9125.2009.00166.x

Kubrin, C.E., \& Stewart, E.A. (2006). Predicting who reoffends: The neglected role of neighborhood context in recidivism studies. Criminology, 44(1), 165-197.doi:http://dx.doi.org/10.1111/j.17459125.2006.00046.x

La Vigne, D., Davies, E., Palmer, T., \& Halberstadt, R. (2008). Release planning for successful reentry: A guide for corrections, service providers, and community groups. Washington, DC: Urban Institute, Justice Policy Center.

Lukies, J., Graffam, J., \& Shinkfield, A.J. (2011). The effect of organizational context variables on employer attitudes toward employability of ex-offenders. International Journal of Offender Therapy and Comparative Criminology, 55(3), 460-475. doi: http://dx.doi.org/10.1177/0306624X09359933

Makarios, M., Steiner, B., \& Travis, L.F. (2010). Examining the predictors of recidivism among men and women released from prison in Ohio. Criminal Justice and Behavior, 37(12), 1377-1391.doi: http:// dx.doi.org/10.1177/0093854810382876

Nally, J.M., Lockwood, S.R., \& Ho, T. (2011). Employment of ex-offenders during the recession. Journal of Correctional Education, 62(2), 117-131.

Nally, J.M., Lockwood, S.R., Ho, T., \& Knutson, K. (2012). The post-release employment and recidivism among different types of ex-offenders with a different level of education: A 5-year follow-up study in Indiana. Justice Policy Journal, 9(1), 1-29. . (2014(a)). Post-release recidivism and employment among different types of ex-offenders: A 5-year follow-up study in the United States. International Journal of Criminal Justice Sciences, 9(1), 16-34.

(2014(b)). Indiana industry sectors that hire ex-prisoners: Implications to correctional education programs. Journal of Correctional Education, 65(3), 43-65.

Nuttall, J., Hollmen, L., \& Staley, M. (2003). The effect of earning a GED on recidivism rates. Journal of Correctional Education, 54(3), 90-94.

Olusanya, O., \& Gau, J.M. (2012). Race, neighbor hood context, and risk prediction. Criminal Justice Studies, 25(2), 159-175.

Phillips, J., \& Land, K.C. (2012). The link between unemployment and crime rate fluctuations: An anal- ysis at the county, state, and national levels. Social Science Research, 41(3), 681-694.doi: http://dx.doi. org/10.1016/j.ssresearch.2012.01.001

Reisig, M.D., Bales, W.D., Hay, C., \& Wang, X. (2007). The effects of racial inequality on Black male recidivism. Justice Quarterly, 24(3), 408-434. doi: http:// dx.doi.org/10.1080/07418820701485387

Rose, C., Reschenberg, K., \& Richards, S. (2010).

The inviting convicts to college program. Journal of Offender Rehabilitation, 49(4), 293-308. doi:

http://dx.doi.org/10.1080/10509671003716092

Rossman, S., \& Roman, C. (2003). Case-managed reentry and employment: Lessons from the opportunity to succeed program. Washington, DC: The Urban Institute, Justice Police Center.

Steurer, S.J., \& Smith, L.G. (2003). Education reduces crime: Three-state inmate recidivism study. Lantham, MD: Correctional Education Association.

Sung, H.E., \& Richter, L. (2006). Contextual barriers to successful reentry of recovering drug offenders. Journal of Substance Abuse Treatment, 31(4), 365-374. doi: http://dx.doi.org/10.1016/j. jsat.2006.05.010

Uggen, C. (2000). Work as a turning point in the life course of criminals: A duration model of age, employment, and recidivism. American Sociological Review, 65(4), 529-546. doi: http://dx.doi. org/10.2307/2657381

U.S. Department of Education. (2012). The Condition of Education 2012. Washington, DC: National Center for Education Statistics.

U.S. Department of Justice. (1998). Chicago's Safer Foundation: A road back for ex-prisoners. Washington, DC: National Institute of Justice, U.S. Department of Justice.

. (2012). Prisoners in 2010. Washington, DC: Bureau of Justice Statistics, Office of Justice Programs.

U.S. Department of Labor. (2012). Labor force statis tics from the current population survey. Washington, DC: Bureau of Labor Statistics.

Vacca, J. (2004). Educated Prisoners Are Less Likely to Return to Prison. Journal of Correctional Education, 55(4), 297-305.

Varghese, F.P., Hardin, E.E., Bauer, R.L., \& Morgan, R.D. (42010). Attitudes toward hiring offenders: The roles of criminal history, job qualifications, and race. International Journal of Offender Therapy and Comparative Criminology, 54(5), 769-782.

Visher, C.A., Winterfield, L., \& Coggeshall, M.B. (2005). Ex-offender employment programs and re- 
cidivism: A meta-analysis. Journal of Experimental Criminology, 1(3), 295-316. doi: http://dx.doi. org/10.1007/s11292-005-8127-x

Wang, X., Mears, D.P., \& Bales, W.D. (2010).

Race-specific employment contexts and recidivism. Criminology, 48(4), 1171-1211.doi: http://dx.doi. org/10.1111/j.1745-9125.2010.00215.x

Winterfield, L., Coggeshall, M., Burke-Storer, M., \& Correa, V. (2009). The effects of postsecondary correctional education-Final report. Urban Institute, Washington, DC: Justice Policy Center.

Susan Lockwood is the Director of Juvenile Education for the Indiana Department of Correction. She has a doctoral degree from Oakland City University, and Masters and Bachelors degrees from Ball State University.

John Nally is the Director of Education for the Indiana Department of Correction. His doctoral degree is from Oakland City University, and his Masters and Bachelors degrees are from Indiana State University.

Taiping Ho is a full professor in the Department of Criminal Justice and Criminology at Ball State University, He completed his doctoral studies at Florida State University.

Katie Knutson is a Senior Consultant at Public Consulting Group in Indianapolis. She has a Masters and Bachelors degree from Ball State University. 